\title{
Preface
}

\section{A BOOK AND TWO HOARDS}

he first two decades of the twenty-first century have seen
an outpouring of interest in hoarding, and in those whose accumulated possessions overwhelm their living spaces, rendering them unusable and often unsafe. Fatal accidents and residential fires across the United States drew considerable attention to hoarding, and cities and towns throughout the nation assembled task forces charged with reducing related safety risks. Hoarding is the subject of documentary and feature films; novels, memoirs, and plays; guides for clinicians and self-help books; installation art, painting, and photography; stand-up and late-night comedy acts; episodes of television forensic dramas, sitcoms, and reality series; academic work in psychology and cultural studies. ${ }^{1}$ With the increasing visibility of hoarding, many who had long considered themselves to be packrats, savers, collectors, and clutter bugs began to form support groups and seek out professional help. Others retreated into their barricaded isolation-now proud of their monumental lots, now embittered by the scorn of their thriftless neighbors, still helpless, still alone. Family members, too, saw their experience reflected in all the talk of hoarding, and founded organizations like "Children of Hoarders" and "Squalor Survivors." 2 
xii

I count myself among their numbers; my father is a hoarder, as was my paternal grandmother. Because of this personal connection, I have been following the cultural discourse with an acute interest that oscillates between: "So that's what that is!" and "Well, it isn't quite like that." As a child, I saw adventure in hoarding; my father and I spent weekends going to yard sales and flea markets. On trash days we would drive around looking for treasure, with mixed results. Once we found a Pepsi machine from the 1950s, which we restored to again dispense glass bottles for a dime. Another time, as I was climbing through some promising curbside heap, my leg was gashed open by something razor-sharp. My grandmother, Fontaine, used to make regular pilgrimages to the town dump down the street from her summer home in Jefferson, Maine. Once she found a box with dozens of pairs of new canvas sneakers in black, white, and orange, and in sizes sufficient to outfit me and my cousins through our walking years of youth. Last time I went to Fontaine's house in Maine-more than thirty years after the wondrous boon-there were still a couple of mismatched shoes left in the closet.

Fontaine died in 2005, leaving behind two houses brimming with the accumulated passion of her life. It had been years since she let anyone into her Auburndale, Massachusetts, home, and its months-long clean out after her death required the labor of her five sons, three daughters-in-law, sixteen grandchildren, as well as the lease of a forty-yard dumpster. We found a rattlesnake's rattle and seventeenth-century ecclesiastical books; stacks indiscriminate with junk mail and stock certificates; decomposing vermin and rotting food buried under creaky antiques. Although Fontaine's eccentricities were a source of laughter at family gatherings, we occasionally recognized something sinister in her accumulations. As when she contracted spinal meningitis from the filth that 
surrounded her, or when my father found her body, comatose, at the foot of a too-cluttered staircase. For all its quirky fascination, there is horror in the hoard, and I shudder to think of the disaster that looms over my father's house, with its exterior dominated by a rotting wood porch crumbling under the weight of salvaged plywood and bookcases, a dozen bicycles, a lawnmower, and the soundboard of a piano; and its interior strewn with the makeshift electrical fixes of overextended extension cords. ${ }^{3}$ Most academic writing grows from personal obsession or intimate pain; my own betrays these roots more materially than some.

I began to explore these roots in writing in January 2010, when I launched If I Were a Hoarder. I conceived of the Tumblr blog as a compendium of all the intriguing detritus, all the irresistible bargains, and all the wondrous objects that would clutter my Berkeley apartment if I were a hoarder. I imagined the site as an exercise in restraint and empathy, a chronicle of my effort to understand the allure of objects, to heed the call of things. I figured I would save money and space-if not time-by transforming this call into writing. Almost immediately, the medium eclipsed the message. Tumblr is a microblogging and social networking platform. Users post video, audio, text, links, and other content that can be easily reposted by others. ${ }^{4}$ Almost 80 percent of Tumblr posts are image files, and I quickly learned that images and videos were more effective in engaging other users than essayistic posts dedicated to appealing objects, my family history, or reflections on the cultural discourse of hoarding. The blog distended haphazardly to include virtually any digital content I stumbled upon that seemed somehow relevant. Hoarders mingled with ragpickers, gleaners, scavengers, misers, fetishists, collectors, archivists, and makers. Discussions of academic works of new materialism, historical materialism, discard studies, and thing theory were punctuated by 
images of abandoned objects, cabinets of curiosity, and cluttered spaces. Photographs of landfills, junkyards, and brimming dumpsters attested to the allure of the broken, the threadbare, and the obsolete.

Though initially intended to ward off what I feared was an inexorable disposition toward hoarding, I soon realized that the unwieldy accumulation of content reproduced the logic of a hoard. If I Were a Hoarder, like many hoards, is an aesthetic object that results from the ceding of authorial or curatorial intention to a series of chance encounters with miscellaneous stuff. The posts were organized according to the date that I chanced upon them and deemed them relevant enough to repost. If I periodically attempted to impose some structure with hashtags, the evolving assortment of such markers and their inconsistent implementation shook its foundations. Any order that might be discerned from properties intrinsic to the posts themselves was secondary to the one established by the chronology of my encounter with them.

Disorganized abundance, which may torment all who write a first book long in the making, is particularly cruel to those who write about accumulation. Writing about hoarding has led me to a range of texts, disciplines, historical periods, and national traditions. I returned to the abandoned spaces of the Tumblr blog and attempted to communicate its meaning without reproducing its logic. If, in this book, I manage to give form to the unbounded content of If I Were a Hoarder, that is an achievement diminished by a personal failure as I have not been able to help my father. I fear that he will not be spared the fate that awaits so many who live in hoards: to be consumed by raging flames or crushed by a domestic avalanche. 